\title{
A Review of Current Intravaginal Drug Delivery Approaches Employed for the Prophylaxis of HIVIAIDS and Prevention of Sexually Transmitted Infections
}

\author{
Valence M. K. Ndesendo, ${ }^{1}$ Viness Pillay, ${ }^{1,4}$ Yahya E. Choonara, ${ }^{1}$ Eckhart Buchmann, ${ }^{2}$ David N. Bayever, ${ }^{1}$ \\ and Leith C. R. Meyer
}

Received 21 November 2007; accepted 4 February 2008; published online 2 April 2008

\begin{abstract}
The objective of this review is to describe the current status of several intravaginal anti-HIV microbicidal delivery systems these delivery systems and microbicidal compounds in the context of their stage within clinical trials and their potential cervicovaginal defence successes. The global Human Immuno-Deficiency Virus (HIV) pandemic continues to spread at a rate of more than 15,000 new infections daily and sexually transmitted infections (STIs) can predispose people to acquiring HIV infection. Male-to-female transmission is eight times more likely to occur than female-to-male transmission due to the anatomical structure of the vagina as well as socio-economic factors and the disempowerment of women that renders them unable to refuse unsafe sexual practices in some communities. The increased incidence of HIV in women has identified the urgent need for efficacious and safe intravaginal delivery of anti-HIV agents that can be used and controlled by women. To meet this challenge, several intravaginal anti-HIV microbicidal delivery systems are in the process of been developed. The outcomes of three main categories are discussed in this review: namely, dual-function polymeric systems, non-polymeric systems and nanotechnology-based systems. These delivery systems include formulations that modify the genital environment (e.g. polyacrylic acid gels and lactobacillus gels), surfactants (e.g. sodium lauryl sulfate), polyanionic therapeutic polymers (e.g. carageenan and carbomer/lactic acid gels), proteins (e.g. cyanovirin-N, monoclonal antibodies and thromspondin-1 peptides), protease inhibitors and other molecules (e.g. dendrimer based-gels and the molecular condom). Intravaginal microbicide delivery systems are providing a new option for preventing the transmission of STIs and HIV.
\end{abstract}

KEY WORDS: HIV/STIs; intravaginal drug delivery systems; microbicides; nanostructures; polymers; prophylaxis.

\section{INTRODUCTION}

Infection with HIV remains an incurable condition $(1,2)$. The highest rate of HIV transmission is through the exposure of the vaginal mucosal surface to HIV during sexual intercourse. Until January 2006, the Joint United Nations Programme on HIV/AIDS (UNAIDS) and the World Health Organization (WHO) estimated that AIDS had caused the mortality of more than 25 million people since it was first recognized, making it one of the most destructive epidemics in recorded history $(3,4)$. The majority of deaths have

\footnotetext{
${ }^{1}$ Department of Pharmacy and Pharmacology, University of the Witwatersrand, 7 York Road, Parktown 2193, Johannesburg, South Africa.

${ }^{2}$ Department of Gynecology and Obstetrics, Chris Hani Baragwanath Hospital, Bertsham, Johannesburg 2013, South Africa.

${ }^{3}$ Brain Function Research Group, School of Physiology, University of the Witwatersrand, 7 York Road, Parktown, Johannesburg 2193, South Africa.

${ }^{4}$ To whom correspondence should be addressed. (e-mail: viness. pillay@wits.ac.za)
}

occurred in sub-Saharan Africa where the prevalence rate for sexually active adults is greater than $35(5-7)$. This culminates in causing the death of economically active adults with the accompanied macro-economic challenges. At present, the current use of antiretroviral treatment reduces both the mortality and morbidity associated with HIV infection, but routine access to antiretroviral medication is not available in all countries. Sexually transmitted infections (STIs) also predispose people to acquiring HIV/AIDS through the interference of the integrity of the vaginal epithelium. The presence of untreated STIs enhances both the acquisition and transmission of HIV by a factor of up to 10 . Thus, effective STI treatment is an important HIV prevention strategy (8-11).

Several therapeutic agents for curing HIV/AIDS have been developed, but, to date none has been proven to be successful. A Reproductive Health Research Unit study by Pettifor et al. (12) showed an extremely high percentage of respondents $(93 \%)$, identified condom use as being an effective preventative measure but $67 \%$ did not use condoms consistently and $31 \%$ had never used condoms. In the wake of this other effective female controlled measures that can 
protect both parties from exposure to HIV/AIDS are needed. The most compelling solution to HIV/AIDS is an effective vaccine. However, after 25 years of research, development of an effective vaccine has remained unsuccessful due to various obstacles including inadequate resources, regulatory capacity concerns, intellectual property issues and mainly the scientific challenges $(8,13,14)$. Therefore, it is likely that the greatest potential for prevention of STIs and HIV/AIDS will lie in the development of effective intravaginal microbicidal delivery systems (Table I).

Studies have shown that the vagina is a suitable site for local and systemic delivery of drugs (14-16). Traditionally, the intravaginal route has been used for the delivery of locally acting drugs such as antibacterials, antifungals, antiprotozoals, antivirals, labor-inducing and spermicidal agents, prostaglandins and steroids. The large surface area, permeability and rich blood supply of the mucous membrane of the vagina, provide significant potential for the delivery of a wide range of compounds, including peptides and proteins, and offers an alternative to the parenteral route of administration for numerous bioactive substances. However, despite all these advantages, the intravaginal route has not been extensively explored as a mode for drug delivery due to menstrual cycle variations (14). Intravaginal drug delivery systems have traditionally been used to deliver contraceptives and drugs to treat vaginal infections. Formulations have included pessaries and tablets designed after the advent of rectal suppositories. The first intravaginal controlled drug delivery system was developed in 1970, using a vaginal ring for the delivery of medroxyprogesterone acetate for contraception (14). However, tablets, creams, and suppositories are now the most conventional formulations in vaginal drug delivery while vaginal rings are more commonly employed for long-term drug delivery.

Recent advances have been made in the area of bioadhesive gels, microparticles and tablets, which show great promise for use as controlled intravaginal microbicide delivery systems (17-19). Numerous hydrophilic polymers and hydrogels have been used in a number of vaginal products $(20-22,23,24)$ that violate the HIV life-cycle at multiple steps, have increased efficacy, limited cross-resistance and minimize microbicide-induced host toxicity $(25,26)$. The objective of this review is therefore to describe the recent developments in intravaginal delivery systems for microbicides employed for the prophylaxis of HIV/AIDS and prevention of STIs.

Table I. Desirable Criteria for Ideal Intravaginal Microbicidal Delivery Systems

Criteria

Simple to manufacture, cost effective and easy to apply thus facilitating patient compliance

Non-irritative and free from producing any physical discomfort

Provide immediate and sustained protection by releasing the

microbicide in a controlled manner over a prolonged period of time

Have suitable vaginal retention and distribution

Be versatile against various pathogens encompassing STIs and HIV

\section{METHODS}

Given the devastating effects of the HIV/AIDS epidemic and the continuing difficulties in developing an effective HIV vaccine, there is a clear scientific rationale for developing alternative methods to prevent STIs and the transmission of HIV infection. Microbicides circumvent many of the immunological difficulties associated with HIV vaccine development and make topical formulations a more realistic goal, especially in the short term $(27,28)$. The most promising strategy currently being pursued is the utilization of intravaginal delivery systems for microbicides (13,26,29-34). Microbicides are chemical substances that when inserted intravaginally prior to sexual intercourse, have the potential to either prevent or reduce the risk of STIs and HIV transmission once released from a delivery system $(24,30,31)$. The potential for developing controlled release formulations for long-term intravaginal delivery of microbicides has recently gained momentum and may overcome challenges relating to compliance, acceptability and efficacy associated with current gel-based formulations (30,35). Furthermore, the emergence of resistant HIV strains and toxic side-effects of current antiretroviral drugs (ARVs) require intravaginal delivery systems with superior safety profiles and potential for improved patient compliance.

An intravaginal microbicidal delivery system combining several mechanisms of preventing the transmission of STIs and HIV would need to possess added effectiveness and less side-effects than a delivery system having a single mechanism (26) (Fig. 1). The challenge is to design a delivery system that is able to provide high concentrations of the microbicidal compound in the vagina over a prolonged period of time (36). Studies have indicated that dosages in first-generation microbicides remain effective only for a few hours and therefore necessitate administration shortly before coitus (37). For controlled, zero-order release sustained over prolonged periods (days extending to months), solid polymeric systems may be the most suitable biocompatible delivery system with the physicochemical nature of the microbicide or drug to be delivered.

\section{Current Intravaginal Microbicide Delivery Methods for Preventing the Transmission of STIs and HIV}

The majority of microbicidal delivery systems for intravaginal administration that have been developed and evaluated in ongoing clinical trials are conventional semi-solid aqueous gels and vaginal ring formulations. These are designed to provide a single dose of a microbicidal agent (38-42). Intravaginal delivery systems for microbicides have been formulated and traditionally include a large variety of pharmaceutical dosage forms such as semi-solids, tablets, capsules, pessaries, liquid preparations, vaginal films, vaginal rings, foams, and tampons. Currently, the maximum duration of drug release for intravaginal microbicidal delivery systems is as follows: (1) Vaginal gels $(6 \mathrm{~h})(42,43),(2)$ vaginal tablets (8 h) $(44,45)$, and (3) vaginal rings (71 days) $(8,46,69)$. Vaginal gels and tablets have rapid release rates which, for effective use, ultimately require administration several times a day. Vaginal rings have adequate release rates but have only been formulated for preventing the transmission of HIV and as a 


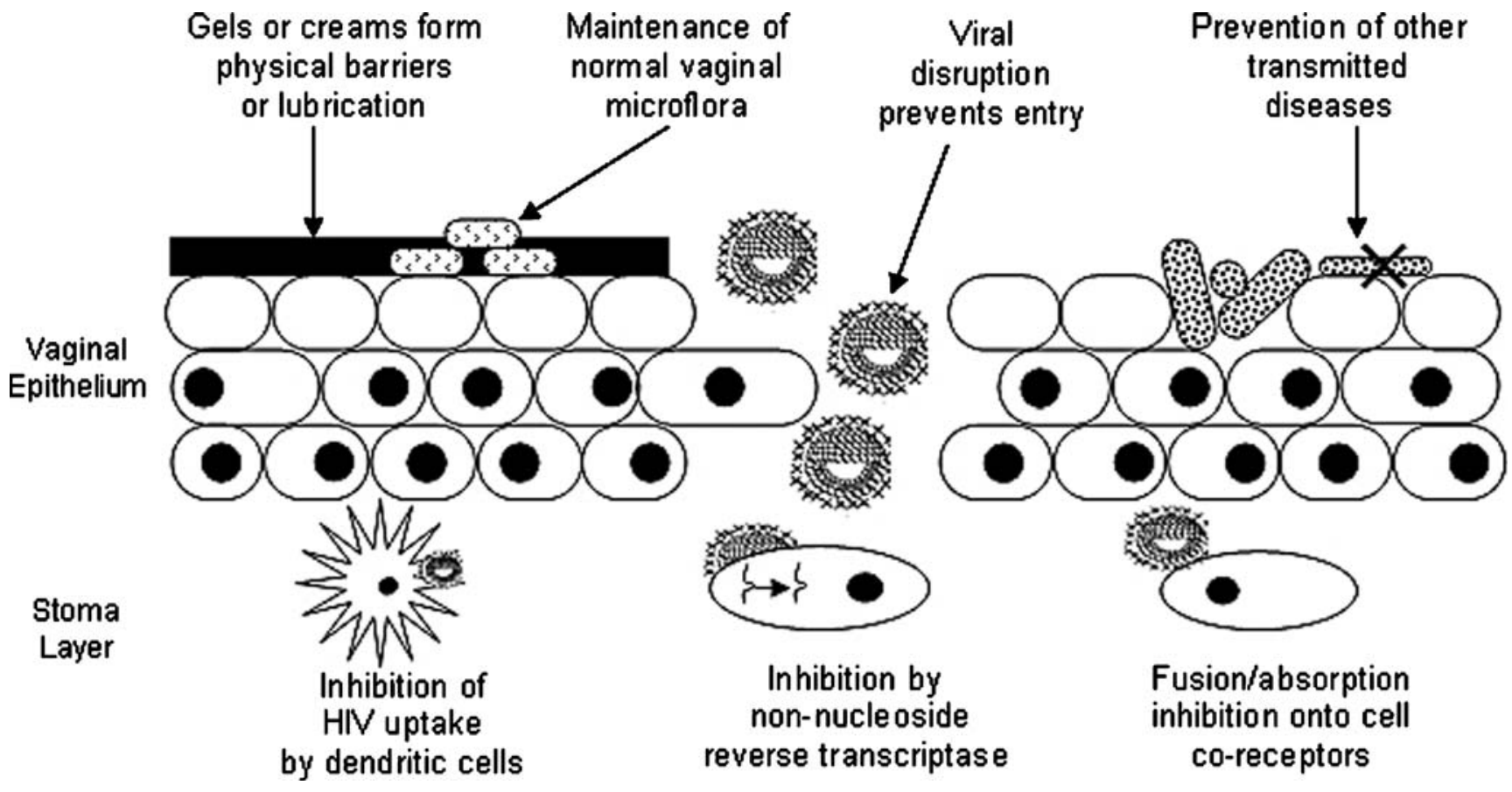

Fig. 1. Schematic depicting the various mechanisms of preventing the transmission of sexually transmitted infections and HIV by employing microbicide delivery systems (adapted: Stone et al. (38))

contraceptive. The most widely used semi-solid preparations for vaginal drug delivery include creams, ointments, and gels $(14,26,37)$.

Over the past decade, there have been major advances in the field of microbicidal delivery with diverse types of delivery systems in various stages of development (47). The ultimate success of an intravaginal microbicide delivery system requires consideration of variables including the microbicidal agent, vaginal physiology and the design of the delivery system. Furthermore, bioavailability is affected by numerous physiological factors, and the ability of the formulation to effectively deliver the microbicide may vary with the menstrual cycle, $\mathrm{pH}$ variations and the presence of co-pathogens $(48,49)$.

Targeting HIV entry into the body is a favored preventative approach as it is the initial step in the process of infection. Several readily available anionic polymers interfere with the entry processes of HIV, and hence these polymers qualify as primary candidates for designing various microbicidal delivery formulations (36). However, few of these formulations have been tested in Phase I/II clinical trials, in HIV-uninfected, and HIV-infected populations (50). Current multi-center Phase I/II safety and Phase II/III efficacy studies are being conducted or planned in different geographical locations, by various groups which aim to design systems for rapid clinical applications.

\section{Design of Intravaginal Microbicide Delivery Systems}

Intravaginal delivery may be designed for administration of microbicides by using an applicator or specifically designed systems for intravaginal administration. In general, based on the delivery system or the microbicide used, drug absorption, distribution and residence time in the vagina may vary. Early studies by Johnson and Masters (51) showed that the microbicide distribution in the vaginal tissue varies considerably with the nature of the delivery system. Solutions, suspensions and foams displayed greater superiority over tablet dosage forms. Ideally, a vaginal delivery system that is intended for localized microbicidal delivery should distribute uniformly throughout the vaginal cavity. Thus, for a local effect to occur in the vagina, semi-solid, or fast dissolving solid systems are required. Bioadhesive delivery systems or intravaginal ring systems are more suited for topical effects. Currently there is no data available regarding the bioavailability of most intravaginal microbicide delivery systems after extended vaginal exposure (50,52). Engineering and materials science may provide critical and new information to the process of designing and developing superior intravaginal microbicide delivery systems. First-generation microbicidal compounds that are currently under investigation are expected to be available within a few years. These systems may only be 50 $60 \%$ effective in delivering microbicides, but even with this efficacy if used (37) by only $20 \%$ of women, in 73 low-income countries, it may still lead to the prevention of 2.5 million new infections during a 3 -year period $(26,37)$.

\section{Creams and Gels}

To date the greatest number of intravaginal drug delivery systems for microbicides, by far, is in the form of creams or gels. Although commonly used for the topical intravaginal delivery of microbicides, these systems are messy, uncomfortable and may not provide an exact dose due to non-uniform distribution and leakage (53). To evaluate the efficacy of a 3-day course of clindamycin vaginal cream in the treatment of bacterial vaginosis, Lamont et al. (54) performed a randomized, placebo controlled trial in pregnant women and found 
that the clindamycin cream was well tolerated and more efficacious than placebo. During the past few years, considerable work has been done on the development of hydrogel controlled release microbicide delivery systems (14-19,55,95). For example, a 3\% alginate gel of nonoxynol-9 has been investigated for intravaginal spermicidal activity (55). The study found that the spermicidal activity and the diffusion of the agent changed with the $\mathrm{pH}$ and osmolarity of the formulation. Recently, a gel microemulsion-based spermicide formulation, phenyl phosphate derivative of zidovudine, with anti-HIV effect, has been developed (56). Multiple intravaginal applications of this drug as a microemulsion gel formulation did not cause any damage in the vaginal epithelium in the rabbit model (57-59).

\section{Tablets and Suppositories}

A large number of intravaginal delivery systems are also available in the form of tablets or suppositories. Some authors use the terms pessaries and suppositories interchangeably and consider vaginal tablets as a separate dosage form. These formulations are designed to melt in the vaginal cavity and release the microbicide over several hours. Suppositories are most commonly used to administer drugs for cervical ripening prior to child birth and for local delivery of various drugs. Vaginal tablets may contain binders, disintegrants and other excipients that are used to prepare conventional oral tablets. Mucoadhesive polymers are sometimes used in tablet formulations to increase the vaginal residence time of the microbicide been delivered. Other vaginal tablet-like formulations are extrapolations of silicone-based vaginal rings. Research groups have studied the release of microbicides from silicone matrices $(60,61)$. Release studies were performed in vitro for up to 1 year and in vivo in rabbits for up to 52 days. Both in vitro and in vivo studies showed consistent release profiles over time, showing that microbicide delivery is controlled by diffusion from the silicone delivery device and was not limited by absorption through the vaginal epithelium.

\section{Vaginal Rings}

Vaginal rings are circular ring-type drug delivery devices designed to release microbicides in a controlled manner after insertion $(8,31,62)$. The advantages of such a device are that it can be controlled by the user; does not interfere with coitus and allows for the continuous delivery of microbicidal compounds. In simple vaginal rings, the microbicide is homogeneously dispersed within a polymeric ring with the surface of the ring releasing the microbicide faster than the inner layers. The key challenge in development of these systems is finding the optimum dose that will deliver the least amount of microbicide necessary to ensure protection. Advances have been made on the original two-layer ring system by adding a third, outer, rate controlling drug-free elastomer layer to minimize the drug concentration spike (63). Much of the methods in vaginal ring literature relates to the commonly used polymer, poly(dimethylsiloxane) or silicone devices, although other elastomeric polymers such as ethylene vinyl acetate and styrene butandiene block copolymers have been tested in recent years $(46,64)$. Most women judged the ring easy to insert and remove, and no side-effects are experienced (65-68).

\section{Bioadhesive Intravaginal Systems}

Most conventional intravaginal formulations however are associated with disadvantages of low retention to the vaginal epithelium, leakage and messiness, thereby causing poor patient compliance. To circumvent these challenges, bioadhesive microbicidal delivery systems are being propagated (67). Bioadhesive polymers that have been used for intravaginal formulations include polycarbophil, hydroxypropylcellulose and polyacrylic acid (70). The first bioadhesive systems for vaginal drug delivery were in the form of tablets for the delivery of bleomycin, an anti-caner agent (70-75). Attempts have also been made to delivery of microbicides using bioadhesive microparticulate vaginal systems $(73-78,99)$. These systems may be a multi-phase liquid or a semi-solid, but have been designed so as not to seep from the vagina like pessary formulations. Table II lists the numerous intravaginal delivery systems that have been identified.

\section{RESULTS AND DISCUSSION}

\section{Dual-Function Polymers Employed in the Design of Intravaginal Microbicide Delivery Systems: As Excipients with Potential Therapeutic Activity}

\section{A Carageenan Vaginal Gel Formulation for HIV and Human Papilloma Virus Inhibition}

Carraguard $^{\mathrm{TM}}$ is a gel-like delivery system comprising carageenan that acts as an absorption inhibitor by coating the vagina. Carageenan is an excipient that is used as a gelling agent and presents as one of the most promising class of potential microbicidal compounds (77-82,86) (Table III). Carraguard $^{\mathrm{TM}}$ has several advantages over other vaginal microbicide delivery systems such as a higher bioavailability, safety, versatility, and economic saving (83). There appears to be no effect on sperm motility (84-86).

Table II. Classification of the Numerous Intravaginal Compounds Delivered Intravaginally

\begin{tabular}{ll}
\hline Classification & \multicolumn{1}{c}{ Compounds } \\
\hline Polymeric & $\begin{array}{c}\text { Carageenan, Monocaprin, Polyacrylic Acid, Lactobacillus, Cellulose Acetate Phthalate, Cellulose Sulfate, Polystyrene } \\
\text { Sulfonate, Naphthalene Sulfonate, Sulfated Polyvinyl Alcohol and Lactic Acid }\end{array}$ \\
Non-Polymeric & $\begin{array}{c}\text { Cetyl Betaine, Myristamine Oxide, Stampidine, Cyanovirin-N, Monoclonal Antibodies, Lyposomes, Thrombospondin-1, } \\
\text { Lime Juice, Yoghurt, Tenofovir and Zidovudine } \\
\text { Dendrimers, Thiourea, Silver, Polystyrene and Sodium Lauryl Sulfate }\end{array}$ \\
\hline
\end{tabular}


Table III. Chemical Structures of Polymeric Microbicide Compounds

Compound

A Combinatory Gel of Carageenan and a Non-Nucleoside Reverse Transcriptase Inhibitor

PC-815 gel is an intravaginal delivery system combining a microbicide containing carageenan with MIV-150. MIV-150 is an NNRTI which prevents HIV-infected cells from replicating $(85,87)$. Pre-clinical tests of MIV-150 have shown a significant increase of activity against HIV-1 primary isolates with no toxic effects. However, it has a low oral bioavailability which makes it an ideal compound for intravaginal delivery, since the chances of causing systemic side-effects become diminished (85). In vitro pharmacological studies have indicated that the PC-815 delivery system has significantly higher activity against HIV than that of the Carraguard ${ }^{\mathrm{TM}}$ system (85).

\section{A Topical Non-Contraceptive Carageenan Gel Formulation}

PC-515 gel is a topical gel formulation containing 3\% $\mathrm{w} /$ $w$ carageenan. It is under development as a non-contraceptive microbicidal delivery system that may offer HIV protection while allowing women to conceive. Zacharopoulos and Phillips (88) showed that PC-515 protected against HSV with an effect superior to many microbicidal delivery systems. The protective effect was seen across a wide range of $\mathrm{pH}$ levels and lasted up to $18 \mathrm{~h}$ (88). PC-515 has undergone developmental trials in humans to ascertain the overall performance of the formulation (89).

\section{A Polyacrylic Acid-Based Gel Formulation}

A polyacrylic acid polymeric gel (BufferGel' ${ }^{\mathrm{TM}}$, ReProtect, LLC, Baltimore, MD, USA), that is currently under Phase II clinical trials for contraception and the prevention of HIV (8). Its maintains the natural acidity of the vagina to ensure survival of lactobacilli that are able to produce lactic acid and hydrogen peroxide which inactivate many pathogens that cause STIs $(82,90)$. BufferGel ${ }^{\mathrm{TM}}$ acidifies semen, thereby destroying sperm cells, HIV and a wide range of STI pathogens during sexual intercourse and thus creates a physical barrier that inhibits the passage of pathogens into the vaginal and cervical epithelium (90-93) (Fig. 2). A similar 

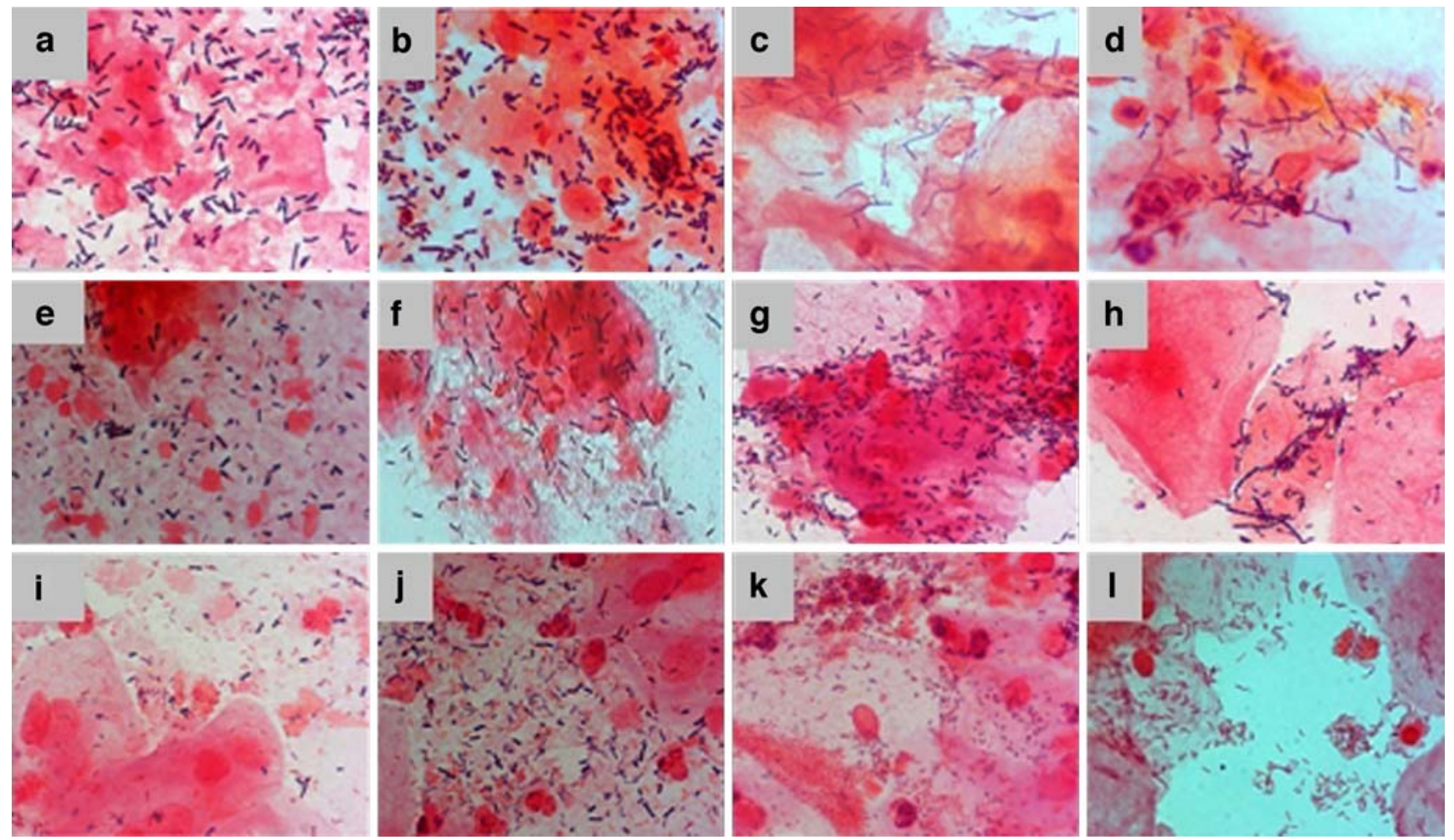

Fig. 2. Smears of vaginal microflora cells. a and b L. crispatus; $\mathbf{c}$ and $\mathbf{d}$ non-L. crispatus; $\mathbf{e}$ and $\mathbf{f}$ L. crispatus and non-L. crispatus; $\mathbf{g}$ and $\mathbf{h}$, Gram+ve rods; $\mathbf{i}$ and $\mathbf{j}$ Lactobacillus and vaginosis bacteria; $\mathbf{k}$ and $\mathbf{I}$ bacterial vaginosis (Verhelst et al. (91))

system includes Acidform ${ }^{\mathrm{TM}}$ gel, an anti-HIV vaginal gel formulation which is currently under Phase III clinical trials (94).

\section{A Lactobacillus Crispatus Soft-Gel Capsule Formulation}

A Lactobacillus crispatus $(L C)$ microbicidal agent (Lactin Vaginal Capsules ${ }^{\mathrm{TM}}$, Gynelogix, Louisville, CO, USA) which acts by re-colonizing the vagina with lactobacillus once released from the soft-gel capsule has been developed (47). $L C$ assists in keeping the vagina free from infection by producing hydrogen-peroxide. Normally, upon disturbing the ecology of the vagina either through infection, douching, or poor hygiene when the vaginal $\mathrm{pH}$ rises above 4.5 , a loss of lactobacilli occurs, resulting in the overgrowth of other bacteria and bacterial vaginosis which is a significant risk for pre-term labor, amnionitis, PID and HIV acquisition $(82,90)$.

\section{Thermosensitive Gel Formulations}

Thermosensitive gels are systems that alter the physical characteristics of the gel with exposure to environmental changes within the vagina usually in the range of $25-37^{\circ} \mathrm{C}$ (96-98). Commonly used thermosensitive polymers for intravaginal microbicide delivery include the polysaccharides, polyacrylamides, poloxamers, polyoxides, polyesters, and a few liposome-based systems. Poloxamer hydrogels represent the most extensively studied thermosensitive polymeric systems, while polysaccharides usually demonstrate good biocompatibility and/or biodegradability (96). Gels, which present mucoadhesive behaviour, are prepared with mixtures of poloxamers and polycarbophil $(96,98,100)$.

\section{Long-Chain Sulfated Polysaccharides and Sulfonated Polymeric Formulations}

A poly(sodium 4-styrene sulfonate) (T-PSS) and cellulose sulfate (UshercellTM, Polydex Pharmaceuticals, Toronto, Canada) microbicidal delivery systems have reached Phase I and III clinical trials respectively (Table III). Both are known to inhibit multiplication or activity of HIV, and various other pathogens (101-106). Gel formulations tested contained 5$10 \% w / w$ T-PSS, hydroxyethylcellulose and propylene glycol (107). T-PSS has been proven safe in animal studies (103, 106). As a result, the US FDA approved an Investigational New Drug (IND) application for both products. However, the Contraceptive Research and Development Program reported that interim data, from a trial where women received Ushercell $^{\mathrm{TM}}$, the prevalence of HIV infection was greater in these women, receiving the delivery system then those receiving the placebo gel (108-111). Thus, these clinical trials have been halted pending the outcome of these investigations.

\section{A Carbomer, Lactic Acid and Naphthalene Sulfonate Gel Formulation}

A gel comprising a synthetic carbomer, a lactate buffer system (Table III) and naphthalene sulfonate as an antiviral agent (PRO 2000 Lexington, MA, USA) is currently under development for the prevention of STIs and HIV $(112,113)$. PRO 2000 ${ }^{\mathrm{TM}} \mathrm{Gel}$ disrupts any interaction of the virus with target cells. Results from in vivo animal studies have shown that PRO 2000 ${ }^{\mathrm{TM}}$ gel is safe and well tolerated (114-116). Currently it is under Phase III clinical trials where it has displayed promising 
results (117). PRO 2000 ${ }^{\mathrm{TM}}$ gels are also compatible with the use of condoms and may even provide more benefits for women worldwide (25).

\section{A Micronized Cellulose Acetate Phthalate Gel Formulation}

Cellulose Acetate Phthalate (CAP) has been used for several decades in the pharmaceutical industry for enteric coating of oral tablets and capsules (Table III). Micronized CAP has shown to adsorb and inactivate HIV-1, HSV and other STIs (118). Earlier studies indicate that a gel formulation of micronized CAP has the potential to be used for topical intravaginal delivery of microbicides for prevention of STIs and HIV (119). It is converted into a gel and therefore does not have to be removed following its application (119). CAP is one of the potential anti-HIV vaginal gel formulations that are under Phase II clinical trials (120).

\section{A Monocaprin-Loaded Hydrogel Formulation}

Monocaprin hydrogel formulations possess potent microbicidal activity against HIV, HSV, Chlamydia trachomatis and Neisseria gonorrhea $(121,122)$ (Table III). In vitro studies have shown that monocaprin gels formulated using sodium carboxymethylcellulose and polyvinylpyrrolidone or carbomer and hydroxypropylmethylcellulose, are virucidal to HSV-1 and less cytotoxic than nonoxynol-9 (123). In vivo studies in mice showed that the gels were non-irritant and non-toxic in the vagina (122). The formulation could be further pursued as intravaginal microbicide delivery systems for the prevention of STIs and HIV.

\section{Polystyrene Sulfonate Vaginal Tablets}

Polystyrene Sulfonate (PSS) is also a microbicide that has been developed as an intravaginal tablet formulation (77) (Table III). When PSS intravaginal tablets were used as a microbicide delivery system it was shown that PSS provided superior antimicrobial activity against HIV and HSV (77). This formulation did not immobilize sperm, was not cytotoxic and did not inhibit normal vaginal microflora. This demonstrates its potential as a safe and effective vaginal microbicide delivery system for the prevention STIs and HIV $(77,124)$.

\section{Non-Polymeric Intravaginal Microbicide Delivery Systems for Preventing the Transmission of STIs and HIV}

\section{A Cetyl Betaine and Myristamine Oxide Combinatory Cream Formulation}

C31G cream (Savvy $^{\mathrm{TM}}$, Cellegy Pharmaceuticals, Inc, San Francisco, CA, USA) comprises a broad-spectrum antimicrobial and spermicidal agent namely cetyl betaine and myristamine oxide that displays activity against bacteria, fungi, yeasts, and enveloped viruses (125) (Table IV). These effects occur once the microbicidal agent diffuses through the cream, which is formulated with hydroxyethylcellulose that also acts as a surface-active microbicide. In Phase III clinical trials, the delivery system has shown the ability to prevent HIV-1 and HIV-2 transmission and also has a desirable contraceptive activity $(49,50)$.
A Non-Nucleoside Reverse Transcriptase Inhibitor-Loaded Gel Formulation

UC781 is a NNRTI that is incorporated into gel formulations (Table IV). Short pre-treatment both of isolated cells and human cervical tissue explants, with low concentrations of UC781 provided a strong barrier to subsequent virus infection by cell-free or cell-associated HIV-1 (126,127). UC781 is readily formulated as an appropriate carrier for vaginal application in the form of Replens ${ }^{\circledR}$ Gel (Anglian Pharma, Hertfordshire, UK). It also has a favorable toxicity profile (126). UC781 warrants further clinical assessment for its use as a topical intravaginal delivery system.

\section{A Nucleotide Analogue-Loaded Gel Formulation}

PMPA Gel (Tenofovir ${ }^{\mathrm{TM}}$, Gilead Sciences, Foster City, CA, USA) is a microbicide delivery system that blocks HIV replication (128). Tenofovir ${ }^{\mathrm{TM}}$ could be absorbed by the vaginal epithelium to prohibit the replication and penetration of the virus in the outer cells of the vaginal wall (Table IV). Preliminary results from studies of Tenofovir ${ }^{\mathrm{TM}}$ are encouraging and indicate that it may be a new microbicide delivery system to consider as part of a potent anti-HIV regimen. Tenofovir ${ }^{\mathrm{TM}}$ may require less frequent dosing than currently available therapies and appears to be active against resistant strains of HIV (83).

\section{A Novel Synthetically Derived Aryl Phosphate-Loaded Gel Formulation}

Stampidine is a derivative of stavudine (Table IV) that is a potent, broad-spectrum anti-HIV agent with potential to be used as a newer class of non-spermicidal microbicides (129). A vaginal gel formulation of stampidine was tested for its potential to cause vaginal mucosal toxicity in New Zealand white rabbits $(129,130)$. Application of $0.5-2.0 \%$ $w / w$ of a stampidine formulation, produced minimal-to-mild vaginal irritation, which is in an acceptable range for a clinical trial (130). Thus, the favorable toxicity profile of intravaginally administered stampidine-containing gel may provide the foundation for its clinical development as a safe and effective broad-spectrum anti-HIV microbicide delivery system.

\section{A Cyanovirin-N Gel Formulation for Chemotherapeutic and Immunoprophylactic Prevention of HIV}

Cyanovirin-N (CV-N) is a novel protein that has generated interest for the chemotherapy of HIV infection (131,132). A possible combined chemotherapeutic and immunoprophylactic approach for preventing HIV may be based upon the concept that continuous exposure of HIV to gp120-binding agents from a gel formulation may diminish glycosylation sites, thus triggering the production of specific neutralizing antibodies to previously hidden gp120 epitopes (133-136). CV-N inhibits the fusion of HIV-infected cells as well as cell-to-cell transmission of HIV-1 infection. CV-N is a promising candidate as a microbicide gel formulation for intravaginal delivery (137). In cell cultures it is non-toxic and resistant to degradation with a shelf-life of at least 6 months (131). 
Table IV. Chemical Structures of Non-polymeric Microbicide Compounds

Cetyl Betaine Reference

Sodium Lauryl Sulfate as an Invisible Condom ${ }^{\mathrm{TM}}$ Gel-Like Formulation

Sodium lauryl sulfate (SLS) is currently under Phase II clinical trials as an entry fusion inhibitor (9) (Invisible Condom $^{\mathrm{TM}}$, Laval University, Infectious Diseases Research Center, Quebec City, QC, Canada). Ward and Ashley (138) were demonstrated that SLS at low concentrations is a potent inactivator of rotavirus and poliovirus. Previous in vitro studies have demonstrated the ability of SLS to inhibit the infective capacity of different enveloped viruses such as HSV1, HSV-2, and HIV-1 (139-141). This suggested that SLS could be a candidate for use as an intravaginal microbicide gel formulation to prevent the sexual transmission of STIs and HIV (139).

\section{Dapivirine Anti-HIV Vaginal Rings}

While most research on microbicides has focused on single-dose and semi-solid topical gels, ring-based delivery systems could reduce the burden of patient compliance. These can provide long-term, controlled release of microbicides that may confer continuous protection against STIs and heterosexually transmitted HIV, and rule out the need for application of the intravaginal microbicidal delivery system near the moment of sexual intercourse $(63,142)$. Dapivirine, which is also known as TMC120, is a potent non-nucleoside reverse transcriptase inhibitor that is the only vaginal ring system used as an intravaginal microbicide delivery system for preventing the transmission of STIs and HIV $(9,142,143)$ (Table IV).

\section{Polyherbal Anti-HIV Praneem-Loaded Vaginal Tablets}

Praneem has been developed as an anti-HIV vaginal tablet formulation. Praneem contains purified extracts of Azadirachta indica also known as the Neem tree. Praneem has preventative activity against STIs in vitro and therefore it has been developed as a possible intravaginal microbicide delivery system. Phase I safety studies on Praneem tablets, 
revealed that the formulation is safe for once daily intravaginal use, for 14 consecutive days, in sexually active uninfected women (113).

\section{Nanotechnology-Based Intravaginal Microbicide Delivery Systems}

\section{A Dendrimer-Based Microbicide Formulation}

SPL2008 (VivaGel ${ }^{\mathrm{TM}}$, Starpharma Ltd., Melbourne, Victoria, Australia) is a dendrimer-based microbicide delivery system in which the dendrimer is not a carrier but an active ingredient $(107,144)$. SPL7013 emerged as the most promising dendrimer after pre-clinical studies, and has been formulated as a gel that is undergoing clinical trials (145). Bernstein et al. (146) showed that a 5\% w/w Carbopol gel can be a suitable vehicle for the intravaginal administration of SPL7013 (147). SPL7013 binds and blocks HIV-1 thereby preventing STIs, including HIV and genital herpes $(108,144,141)$. Phase I trials have shown that VivaGel ${ }^{\text {TM }}$ is safe and well-tolerated. Further trials are being conducted to test its efficacy against genital herpes and HIV $(108,144)$

\section{Silver Nanoparticles Employed as Microbicide Delivery Systems}

Various studies are currently investigating the production of a novel class of nanomaterials called, protein-conjugated noble metal nanoparticles (147-149). The production involves direct conjugation of noble-metal nanoparticles with proteins that may be used in numerous forms including antiviral and antibacterial delivery systems $(148,150)$. Under certain $\mathrm{pH}$ conditions, disulfide bonds of the protein are available for direct bonding with the noble metal nanoparticles. The polypeptide backbone of the protein remains intact and the method does not affect the functional groups of the constituent amino acid residues. Silver nanoparticles take advantage of the microbicide properties of silver with different materials to produce effective microbicide delivery systems for preventing STIs and HIV transmission $(147,148,151)$.

\section{Polystyrene Nanospheres as Microbicide Delivery Systems}

Mucosal secretory $\operatorname{IgA}$ may have an important role in the prevention of HIV-1 transmission during sexual intercourse. Therefore, substances that induce HIV-1-specific IgA antibodies have shown promise for use as prophylactic vaccines against HIV-1 infection. It has been reported that Concanavalin A-immobilized Polystyrene Nanospheres (Con A-NS) could efficiently capture HIV-1 particles on the surface and that intravaginal immunization with the nanospheres induces vaginal anti-HIV-1 $\operatorname{IgA}$ antibodies in mice (152). Thus, application of Con A-NS by intravaginal delivery is a practical approach to promote an effective immunization approach. Likewise, lectin-immobilized polystyrene nanospheres have been synthesized and examined for HIV-1 capturing abilities $(153,154)$.
A Gel-Like Molecular Condom Formulation as a Barrier for STIs and HIV Transmission

The molecular condom is a recently developed anti-HIV vaginal gel (38). The term "molecular condom" arises from the concept that the polymer construct is liquid at room temperature and, when applied intravaginally, spreads and converts to a gel that effectively coats the vaginal wall (38). The gel is designed to release the anti-HIV bioactives upon contact with semen during sexual intercourse. It is a hydrogel sensitive to body temperature and $\mathrm{pH}$, and serves as a "smart semen-triggered vaginal microbicide delivery vehicle." The system is nano-enabled and explores the use of bioresponsive drug delivery by tailoring the physiological and mechanical requirements essential for intravaginal application. The ultimate hope for this technology is to protect women and unborn or nursing children from HIV (38).

\section{Other Microbicidal Compounds Currently Under Investigation}

\section{Thiophen-Thiourea: A Non-Nucleoside Reverse Transcriptase Inhibitor}

PHI-443 is a rationally designed novel thiophen-thiourea NNRTI with potent activity against HIV-1 isolates (94) (Table V). Exposure of human sperm to PHI-443 at doses 30,000 times greater than those that yield effective concentrations against HIV has shown that PHI-443 has no effects on sperm motility, kinematics, cervical mucus penetrability, or the viability of vaginal and cervical epithelial cells. Repeated intravaginal administration of $0.5-2 \% w / w$ of PHI-443 as a gel has been found to be safe in rabbits (94). Thus, PHI-443 has potential as a prophylactic broad-spectrum anti-HIV microbicide without contraceptive activity.

\section{A Secretory Leukocyte Protease Inhibitor}

Secretory leukocyte protease inhibitor (SLPI) is an endogenous antimicrobial agent found in mucosal tissue and saliva, most prominently in mucosal sites open to the external environment. Its original function is believed to be an antiprotease defense against neutrophils at the mucosal surfaces (155). In vitro laboratory studies have shown that SLPI can inhibit HIV entry into $\mathrm{CD} 4^{+}$cells by interacting with targeted cells blocking access as a barrier function. This may provide a reason as to the low rate of HIV infection through oral sex due to the presence of SLPI in saliva. Data from studies of various mucosal tissues such as the mouth, gut, rectum and endocervix, suggest an inverse relationship between infectious HIV and the presence of SLPI (155). Further studies of SLPI as "a natural endogenous product" need to be performed since it has been shown to have the potential to function as an effective microbicide (155-157).

\section{Monoclonal Antibodies as Microbicides}

Monoclonal antibodies are molecules synthesized by the immune system as 'mirror images' of foreign substances (158). A long-range goal in vaginal protection is to develop monoclonal human antibodies in a microbicidal gel for 
Table V. Chemical Structures of Other Novel Microbicide Compounds

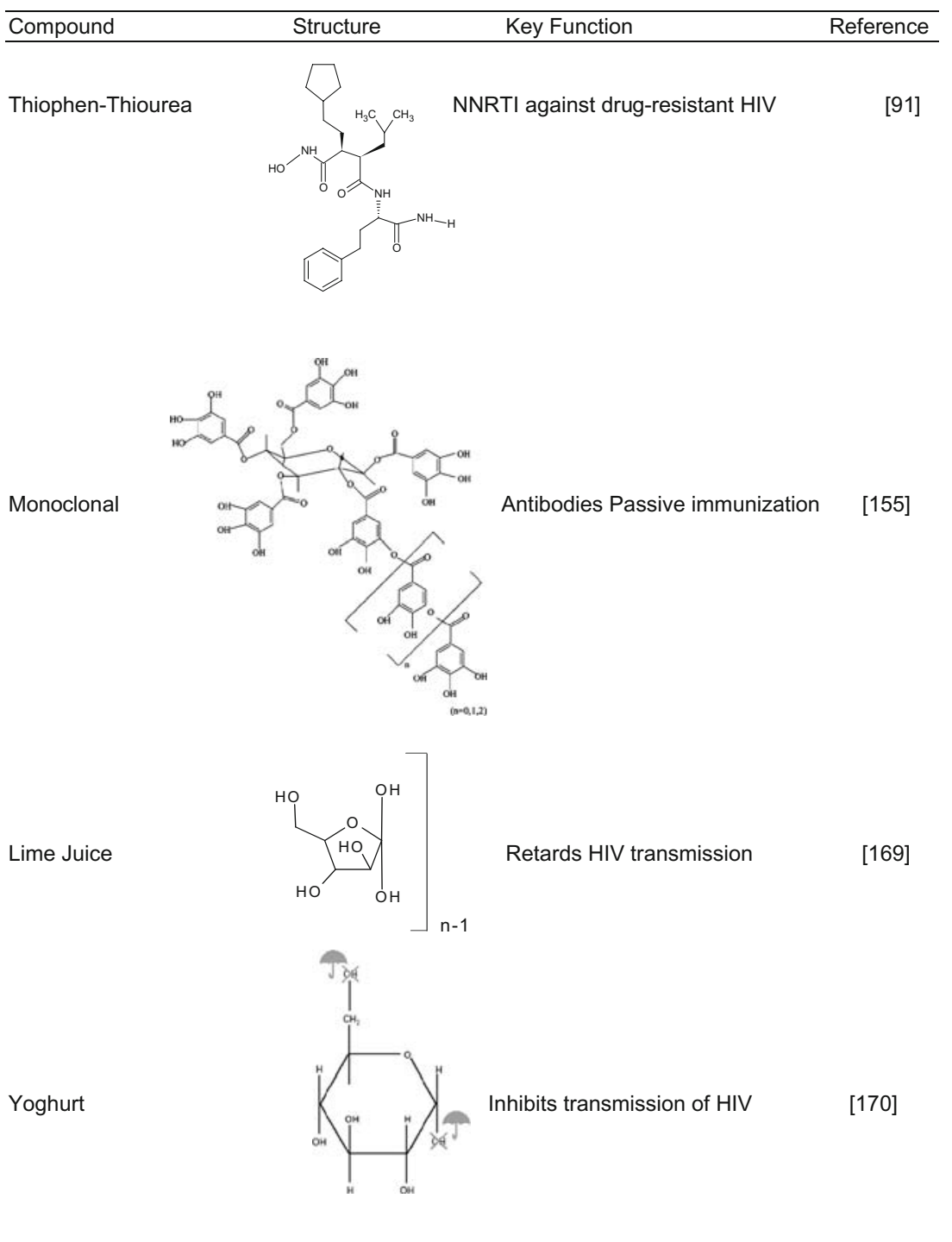

protecting genital skin and epithelia against infections by topical passive immunization. Mucus secretions contain large quantities of antibodies that are highly specific and potent agents for preventing the infectious entry of pathogens (Table V). Monoclonal synthetic antibodies against sperm, HIV, and other STI pathogens can be applied directly to genital skin and epithelia for protection $(159,160)$. This may closely mimic the normal function of antibodies in the mucosal immune system, e.g., antibodies in breast milk help protect the surfaces of the mouth, nose, eyes, and digestive tract of the baby. To date, the results of studies performed indicate that monoclonal antibodies delivered to the vagina may help prevent pregnancy as well as sexual transmission of genital herpes and HIV (161-164).

\section{Thrombospondin-1 as a Barrier to Mucosal Transmission of $H I V-1$}

During an investigation of the physiology of HIV inhibition by human saliva, laboratory studies identified thrombospondin-1 (TSP1) to have potential as a barrier agent against local mucosal transmission of HIV-1 (165-169) (Fig. 3). TSP1 is found in lower concentrations in plasma and most body fluids $(170,172)$, but not in saliva (165). Since TSP1 is a high molecular mass compound, difficult to purify, and labile in the presence of tissue proteases, it is an impractical candidate to be formulated as a localized intravaginal delivery system. Characterization of alternative TSP1 peptide modifications currently under design may identify conformations that are more potent and stable and thus better for localized intravaginal therapy (166).

\section{Short Interfering RNA as Potential Liposomal Microbicide Delivery Systems}

Short interfering RNA (siRNA) is a type of microbicide based on RNA interference (RNAi), a natural selective process for turning off genes, which holds great potential in its ability to treat disease at the genetic level. RNAi is triggered by siRNA molecules that engage a group of cellular proteins, known as RNA-induced silencing complexes (RISC). RISC guides the siRNA to its target messenger 


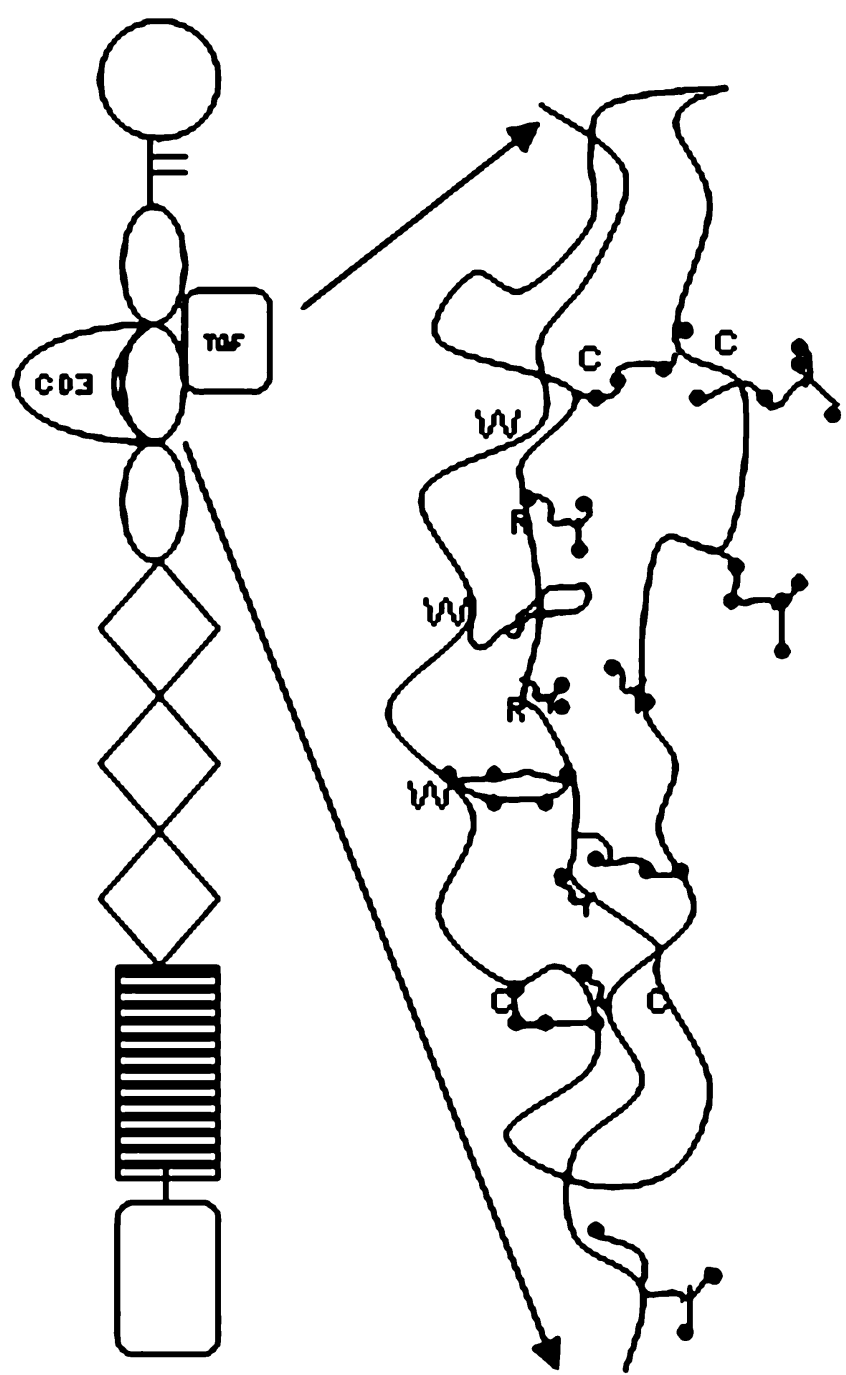

Fig. 3. Schematic of the trimeric-sulphated glycoprotein Thrombospondin-1 with five distinct extracellular matrix adhesion molecules (adapted: Mosher et al. (168))

RNA (mRNA) by complementary base pairing and splits it in a selective fashion, thus halting protein expression or viral replication (170). Currently, in vitro vaginal tissue culture systems have been investigated and work continues with in vivo vaginal xenograft models to determine the optimum dose required for maximum down-regulation of virus replication. In vitro tests utilizing fluorescent tagged siRNA in liposomal delivery systems indicate that siRNAs are absorbed throughout the vaginal tissue $(34,171)$.

\section{Lime Juice as a Microbicide}

Lime juice has a long history as a contraceptive and vaginal douche (Table V). In vitro studies of lemon/lime juice demonstrate that it is an effective microbicide and in vivo primate studies, repeated use of lime juice did not damage the vagina (173). Recent studies have revealed that lime juice, at a concentration of up $20 \% \mathrm{w} / \mathrm{w}$ has a good safety profile for vaginal use. However, there is an urgent need for a systematic study to determine if the use of lime juice can retard HIV transmission. If it slows HIV transmission, lime juice could prove a life saving microbicide. If the effect is modest, lime juice might still prove to be a 'gold standard' microbicide with which artificial microbicides could be compared, short circuiting the need for time consuming expensive placebo controlled trials (173). Thus, further research is needed to determine the safety of lime juice at higher concentrations, and on the effects of lime juice in women that already use it, and on the efficacy of lime juice as an inexpensive and ubiquitous intravaginal microbicide/spermicide used in delivery systems.

\section{Yoghurt as a Microbicide}

Yoghurt may soon be enlisted in the battle against HIV/ AIDS (Table V). Lactobacillus, a harmless bacterium that helps turn milk into yoghurt, has been engineered to make HIV-fighting microbicides. Consuming yoghurt containing Lactobacillus could provide a way for women to fend off HIV if no other means are available (174). As well as appearing in yoghurt, lactobacillus naturally inhabits the human vagina. Lactobacilli play a significant physiological role in the maintenance of the ecological balance mainly due to lactic acid production responsible for maintaining a low $\mathrm{pH}$ level in the vaginal tract. It survives the passage through the gut and can easily traverse the short distance from the anus and colonize the vagina. Once there, the bioengineered bacteria could produce compounds that inhibit transmission of HIV and maintain a normal vaginal $\mathrm{pH}$, thus helping prevent HIV and STIs infection (174-176). Administration of preparations containing a well-characterized probiotic strains to humans could be used to prevent or treat bacterial vaginitis (177).

\section{CONCLUSIONS}

Intravaginal microbicide delivery systems are providing a new option for preventing the transmission of STIs and HIV and this could have considerable public health and economic impact especially in resource-poor countries. As described in this review, numerous safe and effective anti-HIV intravaginal microbicide delivery systems are currently being evaluated at various stages in clinical trials but to date none, which comprise mainly gel formulations, have been found to be fully effective at preventing the transmission of STIs and HIV. Several clinical trials have demonstrated that intravaginal microbicide delivery systems have the ability to protect against the transmission of STIs and HIV but numerous challenges still remain before these systems are used commercially. It is thus anticipated that future research will focus on the design and development of more effective intravaginal microbicidal delivery systems for preventing the transmission of STIs and HIV employing a wide variety of dosage forms with multiple mechanisms of action and microbicidal delivery.

\section{ACKNOWLEDGEMENTS}

Grants from the Norwegian Agency for Development Co-operation (NORAD) and the Faculty Research Committee of the University of the Witwatersrand, Johannesburg, South Africa are acknowledged. 


\section{REFERENCES}

1. HIV and its transmission. Division of HIV/AIDS Prevention, 2003. Available at: Center for Disease Control and Prevention. Accessed May 23, 2006.

2. How HIV is spread. San Francisco AIDS Foundation. Available at: www.iapac.org. Accessed May 23, 2006.

3. O. Pusch, D. Boden, S. Hannify, F. Lee, et al. Bioengineering lactic acid bacteria to secrete the HIV-1 virucide cyanovirin. $J$. AIDS. 40(5):512-520 (2005).

4. Overview of the global AIDS epidemic. Report on the global AIDS epidemic, UNAIDS/WHO. Available at: http://www. cmaj.ca/cgi/content/full/176/12/172. Accessed June 8, 2006.

5. E. Pisani, G. P. Garnett, N. C. Grassly, et al. Back to basics in HIV prevention: focus on exposure. BMJ. 326:1384-1387 (2003).

6. K. R. Malcolm, and D. A. Woolfson. Delivery hope on HIVVaginal rings for controlled release of microbicides. $J$ Controlled Release. 52-55 (2006).

7. J. Berger. Re-sexualizing the Epidemic: Desire, risk and HIV prevention. Dev. Update. 5(3):45-67 (2004).

8. T. J. Brown, A. Yen-Moore, and S. K. Trying. An overview of sexually transmitted diseases. Part 1. J. Am. Acad. Dermatol. 41 (4):511-532 (1999).

9. Sexually transmitted infections (STIs). Drug Digest, 2004. Available at: http://www.drugdigest.org/DD/PrintablePages/Health Conditions/1,20041,550367,00.html. Accessed April 20, 2007.

10. Sexually transmitted Infections (STIs) as a public health issue. Facts sheets, WHO, 2004. Available at: http://www.who.int/ reproductive-health/stis/docs/sti_factsheet_2004.pdf. Accessed April 22, 2007.

11. S. P. Reddy, D. Swart, C. C. Jinabhai, S. L. Amosun, S. James, K. D. Monyeki, G. Stevens, N. Morejele, N. S. Kambaram, R. G. Omardien, and H. W. Van den Borne. Umthenthe Uhlaba Usamila - The South African Youth Risk Behaviour Survey 2002, South African Medical Research Council, Cape Town, 2003.

12. A. E. Pettifor, H. V. Rees, A. Steffenson, L. Hlongwa-Madikizela, C. MacPhail, K. Vermaak, and I. Kleinschmidt. HIV and sexual behavior among young South Africans: a national survey of 15-24 year olds. Reproductive Health Research Unit, University of the Witwatersrand. Available at http://www. rhruco.za/images/Docs/national\%20survey\%20RHRU.pdf. Accessed November, 2007.

13. R. Hatcher, et al. Contraceptive Technology, 18th ed., Ardent Media, Inc., New York, 2004.

14. J. Weber, K. Desai, and J. Darbyshire. The development of vaginal microbicides for the prevention of HIV transmission. PLoS Medicine. 2(5):0392-0395 (2005).

15. K. Verman, and S. Garg. The scope and potential of vaginal drug delivery. PSTT. 3(10):359-364 (2000).

16. D. F. Katz, E. N. Dunmire, M. H. Henderson, D. H. Owen, and A. M. Plenys. Applications of biomedical engineering in reproductive biomedicine: sensing and drug delivery to the lower female reproductive tract. Eng. Med. Biol. Soc. 6 and 30:2656-2658 (1997).

17. C. Tang, C. Yin, Y. Pen, et al. New superporous hydrogels composites based on aqueous carbopol ${ }^{\circledR}$ solution (SPHCcs): Synthesis, characterization and in vitro bioadhesive force studies. Eur. Polym. J. 41:557-562 (2005).

18. C. Valenta. The use of mucoadhesive polymers in vaginal delivery. Adv. Drug Deliv. Rev. 57(11):1692-1712 (2005).

19. M. C. Bonferoni, P. Giunchedi, S. Scalia, et al. Chitosan gels for the vaginal delivery of lactic acid: Relevance of formulation parameters to mucoadhesion and release mechanisms. AAPS PharmSciTech. 7(4):E1-E8 (2006).

20. K. Al-Tahami, and J. Singh. Smart polymer based delivery systems for peptides and proteins. Recent Patents on Drug Delivery and Formulation. 1(1):65-71 (2007).

21. C. W. Lew. Controlled release $\mathrm{pH}$ sensitive capsule and adhesive system and method. US Patent 5364634 (1994).

22. C. Bogentoft, and A. Carlsson. Gel forming liquid carrier composition. US Patent 5492937 (1996).

23. J. R. Robinson, and W. J. Bologna. Use of polycarboxylic acid polymers to treat vaginal infections. US Patent 6017521 (2002).
24. W. J. Lee, J. H. Park, and J. R. Robinson. Bioadhesive-based dosage forms: The next generation. J. Pharm. Sci. 89:850-866 (2000).

25. HIV Vaginal Gel: An overview of PRO 2000. Mom A. Available at: http://www.associatedcontent.com/article/92443/ HIV_vaginal_gel_an_overview_of_pro.html. Accessed March 24, 2006.

26. South Africa: Microbicide trial failure. Thom A. Available at: http://allafrica.com/stories/200702010864.htm. Accessed February 2, 2007.

27. P. Penttinen. Microbicides as an option for HIV prevention, $A$ Report for the International Task Force on Global Public Goods (2005).

28. A. S. Bourinbaiar, R. S. Root-Bernstein, R. Abulafia-Lapid, P. G. Rytik, V. Kanev, A. N. Jirathitikal, and V. G. Orlovsky. Therapeutic AIDS vaccines. Curr. Pharm. Des. 12(16):20172030 (2006).

29. S. N. Joshi, U. Katti, S. Godbole, K. Bharucha, S. Kulkarini, A. Risbud, and S. Mahendale. Phase I safety study of praneem polyherbral vaginal tablet use among HIV-uninfected women in Pune, India. Trans. R. Soc. Trop. Med. Hyg. 99(10):769-774 (2005).

30. K. Best. Microbicide products enter human trials. FHI's Prevention Trials Network. 20(2):1-12 (2000).

31. J. P. Moore, and R. J. Shattock. Preventing HIV-1 sexual transmission-not sexy enough science, or no benefit to the bottom line? J. Antimicrob. Chemother. 52:890-892 (2003).

32. K. R. Malcolm, D. A. Woolfson, C. Toner, et al. Vaginal microbicides for the prevention of HIV transmission. In S. E. Harding (ed.), Biotech and Genetic Eng Rev, Intercept Ltd., Dorset, 2004, pp. 81-121.

33. D. Dhawan, and K. H. Mayer. Microbicides to prevent HIV transmission: Overcoming obstacles to chemical barrier protection. J. Infect. Dis. 193:36-44 (2006).

34. V. Holmes, B. Ramratnam, S. U. Hartmann, et al. Developing a microbicide containing CCR5 siRNA for preventing the transmission of human immunodeficiency virus type 1 (HIV1). Alliance for Microbicides Development. 8(3):1-21 (2007).

35. D. S. Nikolic, E. Garcia, and V. Piguet. Microbicides and other topical agents in the prevention of HIV and sexually transmitted infections. Future Drugs. 5(1):77-88 (2007).

36. A. D. Woolfson, R. K. Malcolm, and R. Gallagher. Drug delivery by the intravaginal route. Crit. Rev. Ther. Drug Carr. Syst. 17:509-555 (2000).

37. A. Benkop-Schnurch, and M. Hornof. Intravaginal drug delivery systems: Design, Challenges and Solutions. Am. J Drug Delivery. 1(4):241-254 (2003).

38. A. Stone. MICROBICIDES: A new approach to preventing HIV and other sexually transmitted infections. Nature Reviews (2002).

39. A molecular condom against AIDS. P. Kiser. Available at: http://unews.utah.edu/p/?r=111706-2, 1-3. Accessed March 26, 2007.

40. S. Di Fabio, J. Van Roey, G. Giannini, et al. Inhibition of vaginal transmission of HIV-1 in hu-SCID mice by the nonnucleoside reverse transcriptase inhibitor TMC120 in a gel formulation. AIDS. 17:1597-1604 (2003).

41. Y. V. Herrewege, J. Michiels, J. Van Roey, et al. In vitro evaluation of non-nucleoside reverse transcriptase inhibitors UC-781 and TMC120-R147681 as human immunodeficiency virus microbicides. Antimicrob Agents Chemother. 48:337-339 (2004).

42. Microbicide Research and Development Database, 2005. Alliance for Microbicide Development. Available at: http://secure. microbicide.org/NetReports/ClinicalTrialsOngoingByProduct. aspx. Accessed July 21, 2007.

43. D. Mitchel. Focus renewed on HIV microbicides. International Health Conference, Canada, 2006.

44. Y. Wang, and H. C. Lee. Effects of intrinsic variables on release of sodium dodecyl sulfate from a female controlled drug delivery system. Int. J. Pharm. 282(1-2):173-181 (2004).

45. E. Bilensoy, A. M. Rouf, I. Vural, M. Sen, and A. A. Hincal. Mucoadhesive, thermosensitive, prolonged-release vaginal gel for clotrimazole cyclodextrin complex. AAPS PharmSciTech. 7 (2):1-13 (2006). 
46. A. El-Kamel, M. Soker, V. Naggar, and S. Al Gamal. Chitosan and sodium alginate-based bioadhesive vaginal tablets. AAPS PharmSciTech. 4(4):1-8 (2002).

47. E. Gavin, V. Sanna, C. Juliano, C. M. Benfero, and P. Giunchedi. Mucoadhesive vaginal tablets as veterinary system for the controlled release of an antimicrobial drug, acriflavine. AAPS PharmSciTech. 3(3):1-7 (2002).

48. J. A. H. van Laarhoven, M. A. B. Kruft, and H. Vromans. In vitro release properties of etonogestrol and ethinyl estradiol from a contraceptive vaginal ring. Int. J. Pharm. 232(1):163-173 (2002).

49. P. F. Harrison, Z. Rosenberg, and J. Bowcut. Topical microbicides for disease prevention: Status and challenges. Clin. Infect. Dis. 26:1290-1294 (2003).

50. L. van Damme. Alliance for microbicide development. Health and Sexuality Microbicides. Special report, 1-8 (2002).

51. L. van Damme, E. Adriens, and G. Ramjee. The evaluation of the local tolerance of vaginal formulations with or without nonxynolol-9 using the slug mucosal irritation test. Contraception. 66(5):369-375 (2002).

52. O. J. D'Cruz, and F. M. UcKun. Clinical development of microbicides for the prevention of HIV infection. Curr. Pharm. Design. 10(3):315-335 (2004).

53. V. E. Johnson, and W. H. Masters. Intravaginal contraceptive study: Phase I. Anatomy. West. J. Surg. Obstet. Gynecol. 70:202207 (1962).

54. D. F. Katz, E. N. Dunmire, M. H. Henderson, D. H. Owen, and A. M. Plenys. Applications of biomedical engineering in reproductive biomedicine: sensing and drug delivery to the lower female reproductive tract. Engineering in Medicine and Biology society. 6 and 30:2656-2658 (1997).

55. L. DuBouchet, J. A. McGregor, M. Ismail, and W. M. McCormack. A pilot study of metronidazole vaginal gel versus oral metronidazole for the treatment of trichomonas vaginalis vaginitis. Sex. Transm. Dis. 25:176-179 (1998).

56. R. F. Lamont, B. M. Jones, D. Mandal, P. E. Hay, and M. Sheehan. The efficacy of vaginal clindamycin for the treatment of abnormal genital tract flora in pregnancy. Infect. Dis. Obstet. Gynecol. 11:181-189 (2003).

57. D. H. Owen, E. N. Dunmire, A. M. Planys, and D. F. Katz. Factors influencing nonoxynol-9 permeation and bioactivity in cervical mucus. J. Control Release. 60:23-34 (1999).

58. S. Yiv, M. Li, O. D'Cruz, and F. M. Uckun. Gel-microencapsulation formulations. USP Patent 064114, June 20, 2006.

59. J. Paavonen. Physiology and ecology of the vagina. Scand. J. Infect. Dis. 40:31-35 (1983).

60. S. S. Cajander, and E. Rylander. Morphometric characteristics of the vaginal epithelium during the menstrual cycle. Gynecol Obstet. Invest. 26:136-144 (1988).

61. H. Pschera, A. Hjerpe, and K. Carlstrom. Influence of the maturity of the vaginal epithelium upon the absorption of vaginally administered estradiol-17-b and progesterone in postmenopausal women. Gynecol. Obstet. Invest. 27:204-207 (1989).

62. D. F. Katz, and E. N. Dunmire. Cervical mucus. Problems and opportunities for drug delivery via the vagina and cervix. $A d v$. Drug Deliv. Rev. 11:385-401 (1993).

63. L. S. Klavinskis, M. Daheshia, K. Karem, E. Manickan, and B. T. Rouse. Intranasal immunization with plasmid DNA-lipid complexes elicits mucosal immunity in the female genital and rectal and rectal tracts. J. Immunol. 1:254-262 (1999).

64. A. D. Woolfson, R. K. Malcom, R. J. Morrow, C. F. Tonner, and S. D. Mc Cullag. Intravaginal ring delivery of the reverse transcriptase inhibitor TMC 120 as an HIV microbicides. Int J Pharm. 325(1-2):82-89 (2006).

65. N. Washington, C. Washington, and C. G. Wilson. Vaginal and intrauterine drug delivery. In N. Washington, C. Washington, and C. G. Wilson (eds.), Physiological Pharmaceutics: Barriers to Drug Absorption, Taylor and Francis, London, 2001, pp. 271281.

66. F. J. M. E. Roumen, and T. O. M. Dieben. Clinical acceptability of an ethylene-vinyl-acetate non-medicated vaginal ring. Contraception. 59:59-62 (1999).

67. C. Novák, L. de la Loge, and E. A. van der Meulen. The combined contraceptive vaginal ring, NuvaRing: an interna- tional study of user acceptability. Contraception. 67:187-194 (2003).

68. B. Harwood, and D. R. Mishell. Contraceptive vaginal ring. Semin. Reprod. Med. 19:381-390 (2001).

69. S. A. Ballagh. Vaginal ring hormone delivery systems in contraception and menopause. Clin. Obstet. Gynecol. 44:106113 (2001).

70. G. Dezarnaulds, and I. S. Fraser. Vaginal ring delivery of hormone replacement therapy-a review. Expt. Opin. Pharmacother. 4:201-212 (2002)

71. J. L. Richardson, and T. I. Armstrong. Vaginal delivery of calcitonin by hyaluronic acid formulations. In E. Mathiowitz, D. E. Chickering, and C. M. Lehr (eds.), Bioadhesive Drug Delivery Systems: Fundamentals, Novel Approaches and Development, Marcel Dekker, New York, 1999, pp. 563-599.

72. S. Hwang, E. O. Wada, T. Yotsuanagi, I. Suhardja, N. F. H. Ho, G. L. Flynn, and W. I. Higuchi. Systems approach to vaginal delivery of drugs: II. In situ vaginal absorption of unbranched aliphatic alcohols. J. Pharm. Sci. 65:1574-1578 (1977).

73. L. Brannon-Peppas. Novel vaginal drug release applications. Adv. Drug Deliv. Rev. 11:169-177 (1992).

74. J. M. Sanders, and H. B. Matthews. Vaginal absorption of polyvinyl alcohol in Fischer 344 rats. Human Exp. Toxicol. 9:71-77 (1990)

75. J. Woodley. Bioadhesion: new possibilities for drug adhesion? Clin. Pharmacokinet. 40:77-84 (2001).

76. K. Knuth, M. Amiji, and J. R. Robinson. Hydrogel delivery systems for vaginal and oral applications: formulation and biological consideration. Adv. Drug Deliv. Rev. 11:137-164 (1993).

77. G. C. Ceschel, P. Maffei, S. L. Borgia, C. Ronchi, and S. Rossi. Development of a mucoadhesive dosage form for vaginal administration. Drug Dev. Ind. Pharm. 27:541-547 (2001).

78. S. Garg, K. Verman, R. A. Anderson, and L. J. Zaneveld Rapidly disintegrating novel bioadhesive vaginal tablets of polystyrene sulfonate (PSS), a potential microbicide formulation [abstract]. International Conference of AIDS [serial online] 2004; Abstract TuPeB4656.

79. M. Perotti, A. Pirovano, and D. M. Phillips. Carageenan formulation prevents macrophage trafficking from vagina: Implications for microbicide development. Biol. Reprod. 69 (3):933-939 (2003).

80. C. H. Lee, R. Bagdon, and Y. W. Chien. Comparative in vitro spermicidal activity and synergistic effect of chelating agents with nonoxynol-9 on human sperm functionality. J. Pharm. Sci. 85:91-95 (1996).

81. W. R. Blakemore, A. D. Ballard, C. J. Sewall, J. J. Modliszewski, and W. A. Bubnis. Inventors. Carageenan based antimicrobial compositions. US Patent 0171053 (2005).

82. A. J. Smit. Medicinal and pharmaceutical uses of seaweed natural products: A review. J. App. Psych. 16(4):245-262 (2004).

83. R. Pearce-Pratt, and D. M. Phillips. Sulfated polysaccharides inhibit lymphocyte-to-epithelial transmission of human immunodeficiency virus-1. Biol. Reprod. 54(1):173-182 (1996).

84. A. Forbes, and P. Harrison. Microbicides. Aids Community Research Initiative. America (2000).

85. M. Justin-Temu, F. Damian, R. Kinget, and G. Van Den Mooter. Intravaginal gels as drug delivery systems. J. Women's Health. 31(7):834-843 (2004)

86. N. Coetzee, A. Hoosen, K. Blanchard, A. de Kock, H. Sebda, B. Friedland, C. Ellerton, N. Nkompela, L Altin, G Ndlovu and K Tweedy. Safety of lambda carageenan microbicides (Carraguard $^{\mathrm{TM}}$ ) in South Africa. University of Cape Town, Medical University of Southern Africa, Population Council and Family Health International. 2006. Available at: http://www.itg.be/ micro2002/downloads/presentations/2Monday_May_13_2002/ Track_B_sessions/Nicol_Coetzee.pdf. Accessed October 17, 2007.

87. A. Fernández-Romero José, T. Mitchell, G. Stuart, et al. Carrageenan/MIV-150 (PC-815), a combination microbicide. Sex. Transm. Dis. 34(1):9-14 (2007).

88. B. C. Buck, C. D. Thompson, J. N. Roberts, et al. Carageenan is a potent inhibitor of papillomavirus infection. PloS Pathogens. 2 (2):0671-0680 (2006) 
89. B. M. Finley, C. J. Plescia, P. F. Harrison, and F. N. Vignes. An analytical overview of the microbicide preclinical and clinical pipeline. AIDS Conference. Toronto Canada; August, 2006.

90. V. R. Zacharopoulos, and D. M. Phillips. Vaginal formulations of carrageenan protect mice from herpes simplex virus infection. Clin. Diag. Lab. Immunol. 4(4):465-468 (1997).

91. P. Maria-Elisa, A. Pirovano, and D. M. Phillips. Carageenan formulation prevents macrophage trafficking from vagina: Implications for microbicide development. Biol. Reprod. 69 (3):933-939 (2003).

92. A. Verhelst. BMC Microbiology. (5)61):DOI 10.1186/14712180-5-61 (2005).

93. E. A. Boskey, M. Jansen, I. K. Merski, I. T. Whaley, T. Moench, and R. Cone. BufferGel ${ }^{\mathrm{TM}}$ favors in vitro growth of lactobacilli while inhibiting BV-associated organisms [abstract]. Johns Hopkins University and ReProtect, Inc. [serial online]. Abstract A07 (2000).

94. E. R. Boskey, R. A. Cone, K. J. Whaley, and T. R. Moench. Origin of vaginal acidity: High $\mathrm{D} / \mathrm{L}$ lactate ratio is consistent with bacteria being the primary source. Hum. Reprod. 16 (9):1809-1813 (2001).

95. J. van de Wijgert, A. Fullem, G. Kelly, et al. Phase I trial of the topical microbicide buffer gel: Safety results from four international sites. J. AIDS. 26(1):21-27 (2001).

96. O. J. D'Cruz, P. Samuel, and F. M. Uckun. PHI-443): A novel noncontraceptive broad-spectrum anti-human immunodeficiency virus microbicide. Biol. Reprod. 71(6):2037-2047 (2004).

97. E. Amarl, A. Perdigao, M. H. Souza, C. Mauck, D. Waller, L. Zaneveld, and A. Faundes. Postcoital testing after the use of acid buffering gel (ACIDFORM) and a 2\% nonoxynol-9 product. Contraception. 70(6):492-497 (2004).

98. M. J. Durrani. Prolonged release bioadhesive vaginal gel dosage form. US Patent 6159491 (2000).

99. C. E. Kast, C. Valenta, M. Leopold, and A. Bernkop-Schnürch. Design and in vitro evaluation of a novel bioadhesive vaginal drug delivery system for clotrimazole. J. Control Rel. 81(3):347354 (2002).

100. D. F. Mosher. Physiology of thrombospondin. Annu. Rev. Med. 41:85-89 (1990).

101. H. Okada. Vaginal route of peptide and protein delivery. In V. H. L. Lee (ed.), Peptide and Protein Drug Delivery, Marcel Dekker, New York, 1991, pp. 633-666.

102. C. Sappey, J. R. Boelaert, S. Legrandpoels, R. W. Grady, and J. Piette. NF-kB transcription factor activation by hydrogen peroxide can be decreased by 2,3-dihydroxybenzoic acid and its ethyl ester derivative. Arch. Biochem. Biophy. 321(1):263-270 (1995).

103. J. A. Simoes, D. M. Citron, A. Aroutcheva, R. A. Anderson, C. J. Chany, D. P. Waller, S. Faro, and L. J. D. Zaneveld. Two novel vaginal microbicides (Polystyrene sulfonate and cellulose sulfate) inhibit Gardnerella vaginalis and anaerobes commonly associated with bacterial vaginosis. Antimicrob. Agents Chemother. 46(8):2692-2695 (2002).

104. R. A. Anderson, K. A. Feathergill, X. H. Diao, M. D. Cooper, R. Kirkpatrick, P. Spear, D. P. Waller, C. J. Chany, G. F. Doncel, B. C. Herold, and D. L. J. Zaneveld. Evaluation of poly (styrene-4-sulfonate) as a preventive agent for conception and sexually transmitted diseases. J. Androl. 21:862-875 (2000).

105. R. A. Anderson, K. A. Feathergill, X. H. Diao, M. D. Cooper, R. Kirkpatrick, W. F. Rencher, D. P. Waller, C. J. Chany, G. F. Doncel, B. C. Herold, and L. J. D. Zaneveld. Preclinical evaluation of sodium cellulose sulfate (Ushercell) as a contraceptive antimicrobial agent. J. Androl. 23:426-438 (2002).

106. N. D. Christensen, C. A. Reed, T. D. Culp, P. L. Hermonat, M. K. Howett, R. A. Anderson, and L. J. Zaneveld. Papillomavirus microbicidal activities of high-molecular-weight cellulose sulfate, dextran sulfate, and polystyrene sulfonate. Antimicrob. Agents Chemother. 45:3427-3432 (2001).

107. B. C. Herold, N. Bourne, D. Marcellino, R. Kirkpatrick, D. M. Strauss, L. J. Zaneveld, D. P. Waller, R. A. Anderson, C. J. Chany, B. J. Barham, L. R. Stanberry, and M. D. Cooper. Poly (sodium 4-styrene sulfonate): an effective candidate topical antimicrobial for the prevention of sexually transmitted diseases. J. Infect. Dis. 181:770-773 (2000).

108. L. J. Zaneveld, D. P. Waller, R. A. Anderson, C. Chany, W. F. Rencher, K. Feathergill, K. Diao, G. F. Doncel, B. Herold, and
M. Cooper. Efficacy and safety of a new vaginal contraceptive antimicrobial formulation containing high molecular weight poly (sodium 4-styrenesulfonate). Biol. Reprod. 66:886-894 (2002).

109. N. Bourne, D. L. Bernstein, J. Ireland, A. J. Sonderfan, A. T. Profy, and L. R. Stanberry. The topical microbicides PRO 2000 protects against genital herpes infection in a mouse model. $J$ Infect Dis. 180:203-205 (1999).

110. L. Highleyman. UsherCell microbicides provides no protection against HIV transmission but VivaGel yields promising early data. 4th International Conference on HIV Treatment, Pathogenesis and Prevention, Sydney, Australia (2007).

111. M. Baba, D. Schols, E. De Clercq, et al. Novel sulfated polymers as highly potent and selective inhibitors of human immunodeficiency virus replication and giant cell formation. Antimicrob. Agents Chemother. 34(1):134-138 (1990).

112. J. Balzarini, and L. van Damme. Microbicide drug candidates to prevent HIV infection. The Lancet. 369:787-797 (2007).

113. E. De Clercq. New anti-HIV agents in preclinical and clinical development. Frontiers in Med Chem. 1(1):543-579 (2004).

114. K. Morrow, R. Rosen, L. Ritcher, A. Emans, A. Forbes, J. Day, $\mathrm{N}$. Morar, et al. The acceptability of an investigational vaginal microbicide, PRO $2000 \mathrm{Gel}$, among women in a phase I clinical trial. J. Women's Health. 12(7):655-666 (2003).

115. S. N. Joshi, S. Dutta, B. Bell, et al. Phase I safety study of $0.5 \%$ PRO 2000 vaginal gel among HIV un-infected women in Pune, India. AIDS Res. Ther. 3(4):2-6 (2006).

116. S. Ruscnis, M. Moonis, D. P. Merril, et al. Naphtalene sulfonate polymers with CD4-blocking and anti-human immunodeficiency virus type 1 activities. Antimicrob. Agents Chemother. 40:234 (1996).

117. L. van Damme, A. Wright, and K. Depraetene. A phase I study of a novel potential intravaginal microbicides, PRO 2000, in healthy sexually inactive women. Sex. Transm. Infect. 76:126 (2000).

118. J. Smith, D. Soma, B. Beverly, P. Albert, et al. Phase I safety study of $0.5 \%$ PRO 2000 vaginal gel among HIV un-infected women in Pune, India. AIDS Res. Ther. 3:4 (2006).

119. K. H. Mayer, S. A. Karim, C. Kelly, et al. The safety and tolerability of a novel vaginal microbicides, PRO 2000/5Gel, in sexually active HIV-uninfected and abstinent HIV-infected women. AIDS. 17:321 (2003).

120. K. H. Manson, M. S. Wyand, C. Miller, and A. R. Neurath. Effect of cellulose acetate phthalate topical cream on vaginal transmission of simian immunodeficiency virus in rhesus monkeys. Antimicrob. Agents Chemother. 44(11):3199-3302 (2000).

121. A. R. Neurath, N. Srick, and Y. Li. Water dispersible microbicidal cellulose acetate phthalate film. BMC Infect. Dis. 3:27 (2003).

122. R. N. Fichora, F. Zhou, V. Ratnan, V. Atanassova, S. Giang, N. Strick, and A. R. Neurath. Anti-human immunodeficiency virus type I microbicides cellulose acetate 1,2-benzene dicarbxylate in a human in vitro model of vaginal inflammation. Antimicrob. Agents Chemother. 49(1):323-325 (2005).

123. H. Thormar, G. Bergsson, E. Gunnarsson, et al. Hydrogels containing monocaprin have potent microbicidal activities against sexually transmitted viruses and bacteria in vitro. Sex. Transm. Infect. 75(3):181-185 (1999).

124. K. T. J. Neyts, E. De Clercq, and H. Thormar. Hydrogels containing monocaprin prevent intravaginal and intracutaneous infections with HSV-2 in mice: Impact on the search for vaginal microbicides. J. Med. Virol. 61(1):107-110 (2000).

125. T. Kristmundsdóttir, S. G. Árnadóttir, G. Bergsson, and H. Thormar. Development and evaluation of microbicidal hydrogels containing monoglyceride as the active ingredient. $J$. Pharm. Sci. 88(10):1011-1015 (2000).

126. L. Maggi, P. Mastromarino, S. Macchia, P. Brigidi, F. Pirovano, D. Matteuzzi, and U. Conte. Technological and biological evaluation of tablets containing different strains of lactobacilli for vaginal administration. Eur. J. Pharm. Biopharm. 50:389395 (2000).

127. F. C. Krebs, R. S. Miller, B. J. Catalone, P. A. Welsh, et al. Sodium dodecyl sulfate and $\mathrm{C} 31 \mathrm{G}$ as microbicidal alternatives to nonoxynol 9): Comparative sensitivity of primary human 
vaginal keratinocytes. Antimicrob. Agents Chemother. 44 (7):1954-1960 (2000).

128. B. Gadi, and M. A. Parniak. Anti-HIV-1 microbicide potential of the tight-binding non-nucleoside reverse transcriptase inhibitor UC781. AIDScience. 1:12 (2001).

129. M. Kerr. NNRTI shows safety as a topical anti-HIV microbicide in animal tests. Antimicrob. Agents Chemother. 51:1608-1615 (2007).

130. E. De Clercq. The role of tenofovir in the prevention of HIV infections. AIDS. 20(15):1990-1991 (2006).

131. O. J. D'Cruz. Stampidine is a potential nonspermicidal broadspectrum anti-human immunodeficiency virus microbicides. Fertil. Steril. 81:831-841 (2003).

132. O. J. D'Cruz, P. Samuel, B. Waurzyniak, and F. M. Uckun. In vivo evaluation of a gel formulation of stampidine, a novel nonspermicidal broad-spectrum anti-HIV microbicide. Am. J. Drug Deliv. 1(4):275-285 (2003).

133. M. R. Boyd, K. R. Gustfson, J. B. Mc Mahon, et al. Discovery of cyanovirin-N, a novel human immunodeficiency virus-ianactivating protein that binds viral surface envelope glycoprotein gp 120: potential application to microbicide development. Antimicrob. Agents Chemother. 41:1521-1530 (1997).

134. E. De Clercq. Current lead natural products for the chemotherapy of human immunodeficiency virus (HIV) infection. Med. Res. Rev. 20:323-349 (2000).

135. J. Balzarini, S. Hatse, K. Vermeire, K. Princen, S. Aquaro, C. F. Perno, et al. Mannose-specific plant lectins from the Amaryllidaceae family qualify as efficient microbicides for prevention of human immunodeficiency virus infection. Antimicrob. Agents Chemother. 48:3858-3870 (2004).

136. J. Balzarini. Targeting the glycans of gp120: a novel approach aimed at the achilles heel of HIV. Lancet Infect. Dis. 5:726-731 (2005).

137. C. C. Tsai, P. Emau, Y. Jiang, B. Tian, W. R. Morton, K. R. Gustafson, et al. Cyanovirin-N gel as a topical microbicide prevents rectal transmission of SHIV89.6P in macaques. AIDS Res. Hum. Retrovir. 19:535-541 (2003).

138. L. Xiaowen, L. A. Lagenaur, and D. A. Simpson. Engineered vaginal Lactobacillus strain for mucosal delivery of the human immunodeficiency virus inhibitor cyanovirin-N. Antimicrob. Agents Chemother. 50(10):3250-3259 (2006).

139. B. R. O' Keef. Biologically active proteins from natural product extracts. J. Nat. Prod. 64:1373-1381 (2001).

140. R. L. Ward, and C. S. Ashley. pH modification of the effects of detergents on the stability of enteric viruses. Appl. Environ. Microbiol. 38:314-322 (1979).

141. S. Roy, J. Piret, N. Gagne et al. Thermoreversible gel containing sodium lauryl sulfate as a potential topical microbicide for the prevention of STDs/HIV. Natl HIV Prev Conf Natl HIV Prev Conf., Atlanta GA 1999.

142. J. Piret, J. Lamontagne, J. Bestman-Smith, S. Roy, P. Gourde, A. Désormeaux, R. F. Omar, J. Juhász, and M. G. Bergeron. In vitro and in vivo evaluations of sodium lauryl sulfate and dextran sulfate as microbicides against herpes simplex and human immunodeficiency viruses. J. Clin. Microbiol. 38:110-119 (2000).

143. M. K. Howett, E. B. Neely, N. D. Christensen, B. Wigdahl, F. C. Krebs, D. Malamud, S. D. Patrick, M. D. Pickel, P. A. Welsh, C. A. Reed, M. G. Ward, L. R. Budgeon, and J. W. Kreider. A broad-spectrum microbicide with virucidal activity against sexually transmitted viruses. Antimicrob. Agents Chemother. 43:314-321 (1999).

144. M. Smith. TMC 120 vaginal ring promising as microbicides carrier. XVI International Conference, Toronto Canada, 2006.

145. J. Nutall, J. Romano, and K. Douville. The future of HIV prevention: Prospects of an effective anti-HIV microbicide. Infect. Dis. Clin. North Am. 21:219-239 (2007).

146. Molecular trees bear fruit. Vogtle. Available at: http://www.rsc. org/chemistryworld/restricted/2007/May/MolecularTreesBear Fruit.asp. Accessed June 9, 2007.

147. Y. Jiang, P. Emau, J. S. Cairns, et al. SPL7013 gel as a topical microbicide for prevention of vaginal transmission of SHIV in macaques. AIDS Res. Hum. Retrovir. 21(3):207-213 (2005).

148. D. I. Bernstein, L. R. Stanberry, S. Sacks, et al. Evaluations of unformulated and formulated dendrimer-based microbicide candidates in mouse and guinea pig models of genital herpes. Antimicrob. Agents Chemother. 47(12):3784-3788 (2003).

149. K. Cho, J. Park, T. Osaka, and S. Park. The study of antimicrobial activity and preservative effects of nanosilver ingredient. Electrochim. Acta. 51(5):956-960 (2005).

150. Protein-noble metal nanoparticles. US Patent 0115495. Yacaman MJ, Elechiquerra JL, Lara HH and Burt JL. Available at: http:// www.freepatentsonline.com/20060115495. Accessed June 5, 2007.

151. S. Pal, Y. K. Tak, and J. M. Song. Does the antibacterial activity of silver nanoparticles depend on the shape of the nanoparticle? A study of the gram-negative bacterium Escherichia coli. Appl. Environ. Microbiol. 73(6):1712-172 (2007).

152. J. L. Richardson, and L. Illum. The vaginal route of peptide and protein drug delivery. Adv. Drug. Deliv. 8:341-366 (1992).

153. E. Barbara, F. Valeria, and E. Fabrizio. Candidate HIV-1 tat vaccine development from basic science to clinical trials. AIDS. 20(18):2245-2261 (2006).

154. T. Akagi, M. Kawamura, M. Ueno, M. Baba, et al. Mucosal immunization with inactivated HIV-1-capturing nanospheres induces a significant HIV-1-specific vaginal antibody response in mice. J. Med. Virol. 69(2):163-172 (2003).

155. T. Hayakawa, M. Kawamura, M. Okamoto, M. Baba, et al. Concanavalin A-immobilized polystyrene nanospheres capture HIV-1 virions and gp120: Potential approach towards prevention of viral transmission. J. Med. Virol. 56:327-331 (1998).

156. A. Carmen, and C. Angel. Effects of surfactants on gel behaviour: Design implications for drug delivery systems. Am. J. Drug Deliv. 1(2):77-101 (2003).

157. R. Bob. Microbicide. Fashioning new tools to deter HIV transmission. Int. Assoc. Physicians AIDS Care. 6(6):157 (2000).

158. N. Cheshenko, M. J. Keller, and V. MasCasullo. Candidate topical microbicides bind herpes simplex virus B and prevent viral entry and cell-to-cell spread. Antimicrob. Agents Chemother. 48(6):2025-2036 (2004).

159. M. J. Keller, A. Tuyam, M. J. Carlucc, et al. Topical microbicides for the prevention of genital herpes infection. $J$. Antimicrob. Chemother. 55(4):420-423 (2005).

160. Microbicides trials get London start. Prevention. Cairns G. Available at: http://www.guscairns.com/. Accessed July 23, 2007.

161. R. A. Cone, and K. J. Whaley. Monoclonal antibodies for reproductive health: Preventing sexual transmission of disease and pregnancy with topically applied antibodies. Am. J. Reprod Immunol. 32(2):114-131 (1994).

162. J. K. Sherwood, L. Zeitlin, K. J. Whaley, R. A. Cone, and W. M. Saltzman. Controlled release of antibodies for long-term topical passive immunoprotection of female mice against genital herpes. Nat. Biotechnol. 14:468-471 (1996).

163. P. E. Castle, K. J. Whaley, T. E. Hoen, T. R. Moench, and R. A. Cone. Contraceptive effect of sperm-agglutinating monoclonal antibodies in rabbits. Biol. Reprod. 56:53-159 (1997).

164. R. A. Cone. Handbook of mucosal immunology. 2nd ed. San Diego: Academic Press by Ogra, Mestecky, Lamm, McGhee, and Bienenstock, 1999.

165. L. Zeitlin, R. A. Cone, and K. J. Whaley. Monoclonal antibodies for preventing mucosal transmission of epidemic infectious diseases. Emerg. Infect. Dis. 5:54-64 (1999).

166. K. Briggs, and L. Zeitlin. An anti-HSV antibody produced in transgenic rice plants prevents HSV-2 infection in mice. Presensted at: Microbicides. 13-16 (2000).

167. R. Crombie, and R. L. Silverstein. Lysosomal integral membrane protein LIMP II binds thrombospondin-1): structurefunction homology with the cell adhesion molecule CD36 defines a conserved recognition motif. J. Biol. Chem. 273: 4855-4866 (1998).

168. D. F. Mosher. Available at: http://www.wisc.edu/molpharm/ faculty/mosher.html. Accessed July 23, 2007.

169. R. Crombie. Mechanism of thrombospondin-1 anti-HIV-1 activity. AIDS Patient Care and STDs. 14(4):211-214 (2000).

170. R. Crombie, K. Kawasaki, K. Hojo, and J. Laurence. Peptides derived from salivary thrombospondin-1 replicate its anti-HIV effect: Potential role in microbicide development. J. AIDS. 27 (1):91-93 (2001).

171. Adams et al. (1995) 
172. P. Bornstein. Diversity of function is inherent in matricellular proteins: an appraisal of thrombospondin-1. J. Cell Biol. 130:503-506 (1995).

173. G. Roumeliotis. SR Pharma claims formulation triumph in siRNA drugs. Alliance for Microbicide Development. 73(5):542547 (2006).

174. P. Cristofaro, and B. Ramratnam. Prevention Strategies: Vaccines and Microbicides 12th Conference on Retrovirus and Opportunistic Infections. Boston, USA, 2005, pp. 22-25.
175. M. Potts, D. Perlman, M. Mandara, N. Prata, and M. Campbell. Is lime/lemon juice an effective microbicide? Int Conf AIDS, University of California, Berkeley, CA, United States, 2004. Abstract C11663.

176. J. Turpin. Yoghurt could help fend off HIV. New Scientist Magazine. 17:2572 (2006).

177. S. P. Voravuthikunchai, S. Bilasoi, and O. Supamala. Antagonistic activity against pathogenic bacteria by human vaginal lactobacilli. Anaerobe. 12:221-226 (2006). 